\title{
Leopoldo Zea e o movimento latino-americano de História das ideias*
}

\section{Leopoldo Zea and the Latin-American movement of History of Ideas}

\author{
EUGÊNIO REZENDE DE CARVALHO \\ Professor Adjunto da Universidade Federal de Goiás \\ Campus II - Samambaia - Sala 40 \\ 74001-970 - Goiania, GO - Brasil - Caixa-Postal: 131 \\ eugenio.carvalho@pq.cnpq.br
}

\begin{abstract}
RESUMO $O$ artigo analisa as etapas de fundação e consolidação de um dos mais importantes movimentos intelectuais da América Latina no século XX - o movimento latino-americano de História das Ideias -, a partir, sobretudo, das ações e escritos de seu principal líder e fundador, o filósofo mexicano Leopoldo Zea Aguilar (1912-2004). Na etapa de fundação, que corresponde à década de 1940, o foco principal é na obra inicial de Zea, bem como em seus primeiros esforços no sentido da articulação e organização institucional do movimento em escala continental. Já na etapa seguinte, que corresponde à década de 1950, é abordado o processo de consolidação orgânica e epistemológica do movimento.
\end{abstract}

* $\quad$ Artigo recebido em 18/06/2009. Aprovado em: 12/09/2009. 
Palavras-chave Leopoldo Zea, História das Ideias, História intelectual Latino-americana

ABSTRACT This article analyzes the stages of foundation and consolidation of one of the most important intellectual movements of Latin America in the twentieth century - the Latin-American movement of History of Ideas -, starting from actions and writings of its main leader and founder, the Mexican philosopher Leopoldo Zea Aguilar (1912-2004). In the 1940s, during the foundation period, the main focus is on the primary work of Zea, as well as on his first efforts to articulate and organize this movement in continental scale. Moreover, in the following stage held in the 1950s, the process of organic and epistemology consolidation of the movement is invoked.

Keywords Leopoldo Zea, History of Ideas, Latin American intellectual History

\section{A etapa de fundação do movimento: a obra inicial de Leopoldo Zea (1940-1944)}

Em 1940, o filósofo espanhol exilado no México, José Gaos (19001969), organiza no Colegio de México um seminário "para o estudo do pensamento nos países de língua espanhola", em convênio com a Faculdade de Filosofia e Letras da Universidade Autônoma do México (UNAM). Gaos pretendia, nesse Seminário, analisar as obras mestras da história do pensamento mexicano, considerando que os mexicanos chegariam a formular um pensamento original baseado no conhecimento e na reflexão sobre o seu próprio passado filosófico. Com base em tal pressuposto, ele promoveu os estudos de história das ideias, num primeiro momento no México e, posteriormente, no âmbito mais geral da Hispano-América.

A preocupação de Gaos pelo estudo da história das ideias ou do pensamento na Hispano-América deve ser compreendida em função da presença - em sua formação e bagagem filosófica - de certas vertentes do historicismo e, sobretudo, das ideias de Ortega y Gasset. Quando era estudante na Faculdade de Filosofia e Letras da então Universidade Central de Madri, Gaos estabeleceu um estreito convívio filosófico com o seu então mestre Ortega, de quem iria assimilar uma série de princípios filosóficos, dentre os quais a tese do "circunstancialismo histórico", 1 da qual se tornou

\footnotetext{
Em um estudo sobre o legado das ideias de Ortega y Gasset na América Latina, através principalmente de José Gaos e das suas influências no interior do movimento da história das ideias latinoamericanas, Antonio Santamaría García analisa especificamente esse circunstancialismo histórico orteguiano. SANTAMARÍA GARCÍA, Antonio. El legado filosófico de José Ortega y Gasset en América Latina. José Gaos y el movimiento de Historia de las Ideas. Anuarios de Estudios Americanos, Escuela de Estudios Hispano-Americanos de Sevilla, n.2, t.I, p.279-308, 1993.)
} 
um dos principais defensores e difusores na Hispano-América. É mediante a incorporação dessa tese que, a partir de sua chegada ao México, Gaos lança as bases de uma história das ideias como uma disciplina autônoma em substituição à história da filosofia tradicional -, valorizando o estudo e a originalidade de certas categorias filosóficas emanadas da realidade cultural hispano-americana e reproduzidas nas obras de seus pensadores. ${ }^{2}$

Com a sua decisiva contribuição, do ponto de vista organizacional e de incentivo à produção e difusão de estudos no campo da história das ideias na Hispano-América, ao lado de seu esforço por lançar as bases e os fundamentos teórico-metodológicos que deveriam guiar a nova disciplina, Gaos se tornou a referência pioneira do foco mexicano do movimento intelectual latino-americano de história das ideias. Sob a sua orientação, formou-se toda uma geração de discípulos no campo de história das ideias, dentre os quais logo se destacou o então jovem filósofo mexicano Leopoldo Zea Aguilar (1912-2004). ${ }^{3}$

A formação filosófica de Zea foi marcada, nos anos 30 e início dos 40, pelos primeiros contatos com Antonio Caso e Samuel Ramos na Faculdade de Filosofia da Universidade Nacional Autônoma do México (UNAM). Este último, além de introduzir-Ihe no pensamento de Ortega y Gasset, o inspiraria mais tarde a tomar a cultura mexicana como objeto de sua reflexão filosófica. Nesse período, Zea também entrou em contato com as preocupações de Francisco Romero sobre as demandas de uma autorreflexão sobre a produção filosófica hispano-americana. Mas foi, sem dúvida, o seu mestre espanhol, José Gaos, que mais influiu, direta e indiretamente, na direção tomada pela formação filosófica inicial de Zea. Num ambiente já caracterizado pela presença do pensamento de Ortega desde a década de 1920, seria a partir de Gaos que Zea aprofundaria seus contatos com o historicismo e o circunstancialismo orteguianos, problematizando o universalismo exclusivista da matriz filosófica europeia. ${ }^{4}$

Sob o incentivo de Gaos, Zea iniciou também seus contatos com outras correntes filosóficas europeias, sobretudo no campo da filosofia alemã (que o próprio Ortega contribuiu para difundir através das publicações na sua

2 Não se quer dizer, entretanto, que a filosofia de Ortega y Gasset tenha sido introduzida no México por meio de José Gaos. Muito provavelmente, a obra de Ortega já fosse conhecida por vários filósofos mexicanos desde a década de 1920. Mas, indubitavelmente, Gaos teve o mérito de difundi-la, tarefa facilitada pela grande receptividade do ambiente intelectual mexicano de sua época, que se achava profundamente envolvido em questões como a da independência cultural.

3 Um detalhado estudo da trajetória intelectual e acadêmica de Leopoldo Zea, que constitui uma importante referência para consulta, foi produzido por LIZCANO FERNÁNDEZ, Francisco. Vida y obra de Leopoldo Zea Aguilar. Cuadernos Americanos. Nueva Época, México, UNAM, v.5, n.107, año XVIII, p.176-188, septiembre-octubre 2004, que publicou também outro trabalho notável de interpretação da obra do filósofo mexicano. LIZCANO FERNÁNDEZ, Francisco. Leopoldo Zea. Una filosofía de la historia. Madrid: Ediciones Cultura Hispánica/Instituto de Cooperación Iberoamericana, 1986.

4 A propósito do processo pelo qual Zea assume a herança ou o legado filosófico de sua época, ver GÓMEZMARTíNEZ, Jose Luis. Edición digital. Proyecto Ensayo Hispánico, 1998, p.1-2. Disponível em: < http://www. ensayistas.org/filosofos/mexico/zea/zea-introdc.htm>. Acesso em 19.12.2005. 
Revista de Occidente). Nesse campo, as teses do historicismo de Dilthey iriam marcar profundamente sua postura filosófica, guiando, inclusive metodologicamente, a sua produção no campo da história das ideias.

Além de Dilthey e Ortega, também foram importantes na formação de Zea a filosofia da história de Hegel, a sociologia dos valores de Scheler, a sociologia do conhecimento de Mannheim, a fenomenologia de Husserl, o existencialismo de Heidegger, bem como o relativismo culturalista de Spengler. Sobretudo em Gaos, Ortega e Dilthey é que Zea iria encontrar uma formulação epistemológica que the abriria uma pauta para a recuperação de um passado que até então havia sido interpretado apenas por meio de perspectivas que respondiam a circunstâncias alheias. ${ }^{5}$ É a partir desse conjunto de influências filosóficas que Zea iria produzir seus primeiros trabalhos no campo da história das ideias, sob a orientação de Gaos.

Em 1942, Zea publica em Cuadernos Americanos ${ }^{6}$ um ensaio de especulação teórica, intitulado En torno a una filosofía americana, ${ }^{7}$ que representou, conforme ele mesmo reconheceu, ${ }^{8}$ o núcleo central de seu pensamento filosófico e sua inserção no debate inaugurado por Alberdi em meados do século XIX sobre o problema da existência de uma filosofia americana. Nesse ensaio, com certas características de manifesto - em que fez referências aos trabalhos recém-publicados por Samuel Ramos (Hacia un nuevo humanismo) e Francisco Romero (Sobre la filosofía en Iberoamérica), considerando-os como um claro exemplo de filosofia americana -, ele já expressava a sua preocupação em historicizar o pensamento e em legitimar as bases de uma filosofia apoiada nessa circunstância regional. Tais referências já evidenciavam sua intenção de estabelecer uma aproximação mais efetiva entre os focos argentino e mexicano de história das ideias, prenunciando o projeto de convergência de ambos que ele próprio levaria a cabo, três anos mais tarde. ${ }^{9}$

Para Raúl Fornet-Betancourt, os primeiros escritos filosóficos de Zea teriam marcado a transformação da filosofia na América Latina, "al proponer una nueva forma de ejercitarla que debe conducir precisamente a su reconfiguración contextual como filosofía americana o filosofía latinoamericana". ${ }^{10}$ Esse autor denominou tal processo de "giro em direção à contextualização

5 GÓMEZ-MARTínEZ, Jose Luis. Leopoldo Zea. El hombre y su obra, p.2.

6 Publicação fundada nesse mesmo ano de 1940, pelo mexicano Jesús Herzog, que se constituiu mais tarde num dos principais veículos de difusão dos trabalhos de história do pensamento e das ideias na América Latina. Essa revista foi dirigida por Leopoldo Zea de 1987 até a sua morte em 2004.

7 Este ensaio constituiu-se numa ampliação de outro texto de Zea, América y su posible filosofia, publicado em 1941, em Letras de México. Zea já havia publicado em 1940 outro texto intitulado El sentido de responsabilidad en la filosofía actual. Juntos, tais textos constituem os seus primeiros escritos filosóficos.

8 ZEA, Leopoldo. Autopercepción intelectual de un proceso histórico. Autobiografía intelectual; Bibliografía de y sobre Leopoldo Zea. Anthropos. Revista de Documentación científica de la cultura, n.89, p.15, octubre/1988.

9 Ver ARDAO, Arturo. La filosofía como compromiso de liberación. Cuadernos Americanos. Nueva Época, México, UNAM, v.4, n.34, año VI, p.229-230, julio-agosto 1992.

10 FORNET-BETANCOURT, Rául. Leopoldo Zea: transformador de la filosofía. Cuadernos Americanos. Nueva Época, México, UNAM, v.5, n.107, año XVIII, p.45, septiembre-octubre 2004. 
da filosofia na América Latina", no qual o papel de Zea teria sido decisivo, em razão de colocar em marcha esse programa de reorientação da filosofia latino-americana, levando em conta a circunstância regional. Seguindo essa perspectiva, fica evidente que tal programa abriu as portas para a recuperação do passado filosófico latino-americano, sob a forma de uma história das ideias. Esse resgate do pensamento, segundo Zea, deveria ser compreendido no diálogo com a própria circunstância ou realidade históricosocial da América Latina, e não a partir de circunstâncias alheias.

Após a publicação de seus primeiros ensaios, em estreito diálogo com Gaos, Zea acata sua sugestão de desenvolver uma tese acadêmica de pós-graduação sobre um tema mexicano, mais especificamente sobre a influência de alguma corrente filosófica no México. Zea decidiu-se pelo positivismo mexicano. ${ }^{11}$ Sob a orientação de Gaos, ele concluiu a primeira parte do trabalho em 1943, pela qual Ihe outorgaram o título de mestre, e a segunda parte no ano seguinte, que lhe valeu o título de doutor pela Faculdade de Filosofia da UNAM. Desses estudos resultaram as publicações, respectivamente, dos livros El positivismo en México (1943) e Apogeo y decadencia del positivismo en México (1944), dentro de uma coleção intitulada Contribución a la historia del pensamiento latinoamericano.

No prefácio de El positivismo en México, Zea iria expor em linhas gerais as motivações, justificativas, objetivos e fundamentos teórico-metodológicos de seu estudo sobre o positivismo mexicano. Inicia afirmando que, num momento de crise cultural como aquele, os diversos países americanos sentiam a necessidade de buscar em sua história, em suas tradições, os elementos para realizar uma cultura que Ihes fosse própria. Em tal contexto, considerava que seria muito importante tratar dos temas da filosofia europeia, sem, contudo, desmerecer os temas filosóficos mexicano ou americano. Estes não deveriam ser encarados simplesmente como malas copias da grande filosofia europeia, mas como produtos de uma experiência humana, não menos humana que a de qualquer europeu. ${ }^{12}$

Ainda nesse mesmo prefácio, Zea procura justificar a escolha do tema de seu estudo - o positivismo no México -, definindo-o como um problema de toda filosofia, pois

el positivismo es un concepto que expresa un conjunto de ideas, las cuales, al igual que otros muchos sistemas filosóficos, pretenden o han pretendido poseer

11 Em um artigo sobre Gaos, de caráter quase biográfico, que retrata a relação entre os dois filósofos, Zea destaca a influência que seu mestre exerceu em seu pensamento de uma forma geral e, em particular, reproduz o diálogo entre ambos no momento em que Gaos tenta convencê-lo da escolha de um tema mexicano para o desenvolvimento da sua tese acadêmica. Para Zea, Gaos Ihe teria ensinado a ver a sua própria história, a do México e a da América Latina - assumindo-as e criando a partir delas e sobre elas -, como ponto de partida de uma história universal da qual também fazia parte. ZEA, Leopoldo. José Gaos. Cuadernos Americanos. Nueva Época, México, UNAM, v.1, n.79, año XIV, p.18, enero-febrero 2000

12 ZEA, Leopoldo. El positivismo en México. México: El Colegio de México, 1943, p.9-10. 
un valor universal. Es decir, pretenden valer como soluciones a los problemas que se plantea el hombre, cualquiera que sea su situación especial o temporal, geográfica o histórica. ${ }^{13}$

No entanto, o tratamento do tema do positivismo, em que pese a pretensão de universalidade comum a todo tema filosófico, deveria colocar em questão as relações entre filosofia e história, ou seja, entre as ideias filosóficas e a realidade de onde elas surgiram. Fica clara aqui a presença do fundamento historicista, de historicização da filosofia. Assim, a problemática que o filósofo mexicano queria levantar já se encontrava implícita no próprio título do trabalho e consistia em considerar o positivismo "no" México, como

en una relación muy particular, en una relación parcial, en relación con una circunstancia llamada México; en relación con unos hombres que vivieron y murieron o viven en México, que se plantearon problemas que sólo la circunstancia mexicana en ciertos momentos de su historia podía plantearles. ${ }^{14}$

Aplicando-se esse pressuposto teórico-metodológico, fundamental para a delimitação de seu tema e objeto de investigação, bem como a problemática que ele comportava, Zea considerou que seria possível saber não apenas como o positivismo foi importado para o México, como os pensadores mexicanos interpretaram essa doutrina - cuja pretensão era universal -, mas a forma peculiar com que foi interpretada e utilizada pelos mexicanos. O problema epistemológico a ser enfrentado consistia então em conhecer o que de "mexicano" havia nas interpretações dos pensadores mexicanos da doutrina positivista, operação que passava pela definição de onde e como buscar tal conhecimento. Para esse problema, Zea apresentou a seguinte solução:

Para poder saber lo que de mexicano hay en esta interpretación, es menester ir a nuestra historia, a la historia de los hombres que se sirvieron del positivismo para justificar ciertos intereses, que no son los mismos de los positivistas creadores del sistema. ${ }^{15}$

E foi assim que Zea realizou a sua pesquisa empírica sobre o positivismo mexicano, buscando corroborar suas hipóteses com fatos históricos e com a análise dos textos dos principais positivistas mexicanos. Dividiu o seu trabalho em duas partes, sendo que cada uma correspondeu a um livro. 
Centrando-se na análise da obra de Gabino Barreda ${ }^{16}$ e de seus discípulos, a primeira parte, que corresponde ao livro El positivismo en México, trata da origem e desenvolvimento do positivismo no México, antes que tal doutrina se transformasse em um instrumento de política ativa. Zea analisa ainda, nessa primeira parte, os ideais almejados pelos positivistas mexicanos, bem como os obstáculos encontrados para a realização de seu projeto. Já na segunda parte, que corresponde ao livro Apogeo y decadencia del positivismo en México, Zea investigou o positivismo, principalmente em sua expressão política, buscando identificar suas conexões com o regime porfirista, assim como sua adaptação aos interesses desse regime. Concluiu por fim a sua obra com a análise da decadência do positivismo como doutrina a serviço da circunstância mexicana. ${ }^{17}$

A repercussão gerada, nos meios intelectuais e acadêmicos latinoamericanos, pela publicação desses dois livros de Zea foram surpreendentes, contribuindo sobremaneira para projetar o seu nome para além das fronteiras mexicanas. A partir de então, ele despontou como uma referência no campo da história das ideias na América Latina, e suas obras passaram a ser consideradas como um paradigma nesse campo de estudos. O próprio Gaos $^{18}$ chegou a afirmar que esses dois livros constituíam um "modelo em matéria de história das ideias no México", e ainda "um modelo de explicação e compreensão das ideias filosóficas por meio de suas circunstâncias". Destacando a relevância desses trabalhos iniciais de Zea, Ardao afirmou que

fundaron ellos la investigación monográfica pormenorizada, bajo una concepción y una metodología nuevas. A través del análisis de una corriente y una época capitales en la vida del país, como fueron las del positivismo, ponían en evidencia la estrecha conexión entre las ideas filosóficas y la historia general. ${ }^{19}$

Com a publicação das suas primeiras obras nesse campo de estudos, Zea contribuiu decisivamente para a configuração e delimitação dos perfis teóricos e metodológicos que deveriam guiar a nova disciplina história das ideias. Seu próximo projeto seria estender seus estudos sobre o positivismo no México para a América Latina, tarefa a qual se dedicaria nos anos seguintes e que se daria de forma paralela ao seu propósito de integrar, organizar, promover e difundir os estudos sobre história das ideias nos vários países da América Latina. Tal esforço selaria a etapa de nascimento do movimento propriamente dito.

16 Gabino Barreda (1820-1881), médico, filósofo e político mexicano, ex-aluno de Augusto Comte em Paris e um dos principais responsáveis pela introdução do positivismo no contexto filosófico mexicano, com grande influência no governo do presidente Benito Juárez.

17 ZEA, Leopoldo. El positivismo en México, p.51.

18 GAOS, José. En torno a la filosofía mexicana. México: Porrúa y Obregón, 1952, vol.1, p.22.

19 ARDAO, Arturo. La inteligencia latinoamericana. Montevideo: Universidad de la República, 1987, p.105-106. 


\section{A viagem de Zea pela América (1945-1946) e a fundação do Co- mitê de História das Ideias (1947)}

Logo após a publicação dos seus primeiros livros sobre o positivismo no México, Zea foi incentivado por Gaos a estender seu estudo ao âmbito latino-americano, incorporando ainda a etapa prévia do romantismo. Seria, assim, uma ampla investigação sobre a história das ideias na América Latina. ${ }^{20}$ Graças aos contatos estabelecidos por Alfonso Reyes com a Fundação Rockfeller, nos Estados Unidos, Zea é agraciado com uma bolsa de estudos para desenvolver uma pesquisa sobre o romantismo e o positivismo nos diferentes contextos culturais dos países latino-americanos. Tal apoio permitiu que, entre 1945 e 1946, Zea visitasse os Estados Unidos e vários países da América do Sul, consultando fontes e estabelecendo contatos e intercâmbios com inúmeros intelectuais desses países que muito o ajudariam na sua tarefa de pesquisador.

A partir de alguns contatos prévios, Francisco Romero, da Argentina, indica a Zea uma lista de filósofos de vários países latino-americanos, para que ele os visitasse pessoalmente. Com esse apoio de Romero, Zea iniciou o seu trabalho empírico de investigação, visitando em Lima o filósofo peruano Francisco Miró Quesada (1918-), com quem estabelece uma profunda amizade. Já em Buenos Aires, encontra-se pessoalmente com Francisco Romero e seu irmão, José Luis Romero (1909-1977), além de outros jovens intelectuais argentinos, como o historiador Gregorio Weinberg (1919-2006). O contato pessoal entre Zea e Francisco Romero significou, na prática, a convergência definitiva entre os focos mexicano (estimulado principalmente por Gaos) e argentino (fomentado sobretudo por Romero), unificando o até então disperso movimento de história das ideias nesses países em um só movimento orgânico, que posteriormente abrangeria outros focos na América Latina. Tal conexão filosófica, segundo Ardao, ultrapassou o nível estritamente historiográfico e alcançou um espírito de comunidade, diante dos estreitos laços pessoais estabelecidos a partir da viagem de Zea. ${ }^{21}$

Ainda em 1945, Zea foi a Montevidéu, onde se encontrou, entre outros, com o filósofo uruguaio Arturo Ardao, que se tornaria seu grande amigo, interlocutor e colaborador. Dando continuidade ao seu propósito de procurar estabelecer contatos e diálogos com nomes da intelectualidade latinoamericana - interessados, como ele, no resgate do passado filosófico da América Latina -, Zea se encontrou, no Brasil, com João Cruz Costa (19041978); no Chile, com Enrique Molina (1871-1964); na Bolívia, com Guillermo Francovich (1901-1990); na Colômbia, com Danilo Cruz Vélez (1920-2008) e

20 ZEA, Leopoldo. José Gaos, p.20.

21 Uma mostra sugestiva dos primeiros contatos entre os focos mexicano e argentino é apresentada por Ardao em um artigo em que compila uma série de diálogos e referências recíprocas que fizeram entre si Gaos, Romero e Zea. ARDAO, Arturo, La filosofía como compromiso de liberación, p.234. 
Germán Arciniegas (1900-1999); no Equador, com Benjamin Carrión (18971979); na Venezuela, com Mariano Picón Salas (1901-1965).

De acordo com Ardao, ${ }^{22}$ essa viagem de Zea, ${ }^{23}$ no contexto do que chamou de "década fundadora" (1940), constituiu "um capítulo singular da história da historiografia das ideias na América Latina". Os contatos que Zea estabeleceu em sua viagem foram fundamentais para a integração de toda uma geração de pensadores latino-americanos, reunidos em torno da preocupação comum de recuperar e revalorizar o passado filosófico e cultural em cada um de seus países. Tal rede de investigadores, posteriormente ampliada mediante a incorporação de vários outros intelectuais de diversas nacionalidades, logo se transformaria na base orgânica e institucional do movimento latino-americano de história das ideias, marcando a projeção continental do plano de Zea, reforçada por um significativo suporte editorial.

Um dos resultados mais significativos dessa viagem de Zea se deu na esfera institucional. Em 1947, a Comissão de História do Instituto Panamericano de Geografia e História (IPGH), por solicitação de seu presidente, Dr. Silvio Zavala, criou o Comitê de História das Ideias na América, cuja presidência coube a Leopoldo Zea. ${ }^{24} \mathrm{~A}$ principal atividade desse Comitê seria a preparação e posterior publicação de uma história das ideias de cada uma das nações americanas, dentro do projeto mais amplo de uma história das ideias contemporâneas na América, patrocinada pelo IPGH e pela Fundação Rockefeller, com o apoio editorial da Fondo de Cultura Económica, que criou para tanto a coleção Tierra Firme. ${ }^{25}$ Assim, nos anos seguintes ao de sua fundação, o Comitê de História das Ideias do IPGH teve como programa inicial levar adiante uma tarefa de tipo continental, reunindo todos os investigadores que já vinham trabalhando sobre a temática e

22 ARDAO, Arturo. La historiografía de las ideas en Latinoamérica. Latinoamérica. Anuario de Estudios Latinoamericanos, México, UNAM, 1977, p.32.

23 O filósofo peruano Francisco Miró Quesada, que viria a se constituir numa importante figura dentro do movimento latinoamericano de história das ideias, produziu um importante registro acerca dessa viagem de Zea e de seus objetivos. MIRÓ QUESADA, Francisco. Despertar y proyecto del filosofar latinoamericano. México: Fondo de Cultura Econômica, 1974, p.7-21.

$24 \mathrm{O}$ IPGH, com sede no México, havia sido fundado em 1928, na VI Conferência Internacional Americana, realizada em Havana, Cuba. Em 1949 foi firmado um convênio entre esse Instituto e a Organização dos Estados Americanos (OEA). Entre os objetivos do IPGH, destacam-se: o fomento, coordenação e difusão de estudos na sua área de abrangência que sejam de interesse para a América; promoção de projetos, investigações e publicações nas suas áreas específicas de abrangência; promoção da cooperação, em suas áreas de trabalho, dos institutos existentes nos países membros entre si e entre eles e as organizações internacionais afins. Formavam parte ainda da Comissão de História do IPGH os seguintes comitês: Antropologia, Arquivos, Bibliografia, Folclore, Movimento Emancipador, Programa de História da América e Revisão de Textos.

25 O apoio dado pela Fundação Rockefeller à Comissão de História do IPGH permitiu, durante certo tempo, que os investigadores pudessem preparar os seus trabalhos e entregá-los à Comissão de História do IPGH para publicação. O secretário da referida Comissão Ernesto Torre de Villar apresentou em 1959 uma lista desses títulos. TORRE DE VILLAR, Ernesto. El primer Seminario de Historia de las Ideas en América. Revista de Historia de las Ideas. Editorial Casa de la Cultura Ecuatoriana, Quito, n.1, p.13-14, 1959. (Edición facsimilar. Colección de Revistas Ecuatorianas. Banco Central del Ecuador, n.1 y 2, 1984.). 
incentivando a formação de novos, viabilizando com tal esforço coletivo a formação de uma biblioteca de história das ideias por países. ${ }^{26}$

Tais investigações foram possíveis graças à colaboração do grupo de intelectuais latino-americanos, com os quais Zea havia se encontrado em sua viagem nos anos 1945-1946, além de outros contatados em posteriores visitas do filósofo mexicano pela América Latina. O referido Comitê passaria a contar, assim, com distintas filiais em vários países americanos que desenvolveriam importantes ações no desenvolvimento, incentivo e difusão da história das ideias.

Outro resultado importante da viagem de Zea: o desdobramento de seu projeto de investigação sobre o positivismo latino-americano, que teria inclusive motivado sua peregrinação pela região. Publicado em 1949, seu livro Dos etapas del pensamiento en Hispanoamérica: del romanticismo al positivismo, foi reeditado em 1965, numa versão ampliada, sob o novo título El pensamiento latinoamericano. Conforme Zea, ${ }^{27}$ a primeira das duas etapas do pensamento hispano-americano, analisada em seu livro de 1949, se referia à etapa dos "românticos", dos "negadores do passado histórico como expressão da dominação ibérica", dos "emancipadores mentais" dispostos a eliminar seu próprio passado e se auto-impor um modelo de futuro que, sendo-Ihes estranho, se transformaria numa nova justaposição dominante. Por sua vez, a segunda etapa era formada pelos "construtores da nova ordem", inspirados no positivismo, que buscavam "fazer de seus povos cópias" - "desgraçadamente apenas cópias" - de formas de uma ordem estranha à sua própria realidade. ${ }^{28}$

Dessa forma, em Dos etapas del pensamiento en Hispanoamérica, embora assinalasse as diversidades nacionais, Zea iria reconhecer então inúmeras semelhanças entre as expressões do pensamento positivista nos diversos países da Hispano-América por ele estudados, a ponto de se poder falar de um positivismo hispano-americano. E o mesmo se poderia dizer, segundo ele, a respeito da etapa prévia ao positivismo, também comum a toda a região, denominada romântica ou "romanticista". Esse livro representou, enfim, a aplicação, na dimensão hispano-americana, dos mesmos recursos teóricos e metodológicos utilizados antes por Zea em seus trabalhos sobre o positivismo mexicano, reforçando a orientação historicista e orteguiana que guiava sua produção intelectual. Consolidavase, em decorrência, o modelo teórico-metodológico da história das ideias por ele projetado e praticado.

26 ROIG, Arturo Andrés. La "Historia de las Ideas" cinco lustros después. Estudio introductorio de la edición facsimilar de los números 1 y 2 de la Revista Historia de las Ideas n.1 y 2, p.II-III, 1984.

27 ZEA, Leopoldo. El pensamiento latinoamericano. 3ªed. México: Ariel/Barcelona: Esplugues de Llobregat, 1976, p.8-9.

28 ZEA, Leopoldo. El pensamiento latinoamericano, p.9. 
Por outro lado, a publicação de Dos etapas marcaria na biografia intelectual de Zea, além da ampliação de estudos do nacional em direção ao continental, o início de um processo de sua transição progressiva de historiador da filosofia a filósofo da história. Ou seja, de sua transição da história das ideias em direção a uma filosofia da história latino-americana, como núcleo central de suas preocupações intelectuais. De qualquer forma, o livro Dos etapas - ao lado da suas reedições ampliadas publicadas posteriormente e dos estudos precedentes sobre o positivismo mexicano - integra um conjunto de obras que representam a etapa mais importante e significativa da produção de Leopoldo Zea como historiador das ideias.

\section{Etapa de consolidação: o Seminário de História das Ideias (1956) e a Revista de História das Ideias (1959-60)}

Dentro do processo de consolidação do movimento latino-americano de história das ideias, ao longo da década de 1950, destaca-se a iniciativa do Comitê de História das Ideias, vinculado ao Instituto Panamericano de Geografia e História (IPGH), de organizar o / Seminário de História das Ideias na América, em Porto Rico, em 1956. Dele participaram, além do próprio Leopoldo Zea, os mexicanos Samuel Ramos e Abelardo Villegas Maldonado, o argentino José Luis Romero, o uruguaio Arturo Ardao, o peruano Francisco Miró Quesada, o brasileiro João Cruz Costa e o italiano Antonello Gerbi, entre vários outros.

Esse evento representou a primeira grande iniciativa concreta do Comitê no sentido de forjar um debate pioneiro e o balanço geral dos estudos até então realizados, ${ }^{29}$ além de se tornar uma oportunidade única de contato e intercâmbio entre os diversos investigadores, bem como um espaço de apresentação de suas comunicações. Foram relevantes as seguintes deliberações: a proposta de fundação de comissões nacionais e a criação de um órgão editorial periódico que pudesse veicular os trabalhos do Comitê.

O outro importante marco no processo de consolidação do movimento latino-americano de história das ideias foi a intensificação das iniciativas editoriais, com destaque para a criação, em 1959, da Revista de Historia de las Ideas en América. Tal publicação - dirigida por Leopoldo Zea ${ }^{30}$ - foi resultado de um acordo celebrado entre a Casa de la Cultura Ecuatoriana e

29 Para Roig "ali um conjunto de estudiosos, reunidos em um seminário se colocaram, pela primera vez, a tarefa de fazer o que até então parecia uma forma nova de fazer história: a história das ideias". ROIG, Arturo Andrés. Historia de las ideas, Teoría del discurso y Pensamiento latinoamericano. Bogotá: Universidad de Santo Tomás/ Ediciones USTA, 1993, p.11. Segundo o norte-americano Harold Eugene Davis, as comunicações apresentadas no Seminário de Porto Rico sugerem o esforço de uma síntese que vai mais além do esforço de produção de ideias restritas ao âmbito nacional. DAVIS, Harold Eugene. La historia de las ideas en Latinoamérica. Latinoamérica. Anuario/Estudios Latinoamericanos, n.2, p.13, 1969

30 Além de Zea como seu Diretor, a Revista de Historia de las Ideas tinha como Secretário Abelardo Villegas, como redatores João Cruz Costa (Brasil), Monelisa Pérez Marchand (Porto Rico), Santiago Vidal Muñoz (Chile), Max Savelle (Estados Unidos) e Ernesto de la Torre (México) e, por fim, integravam seu Conselho Consultivo José Luis 
o Comitê de História das Ideias da Comissão de História do IPGH. Os dois primeiros números mantiveram periodicidade anual, mas, por uma série de dificuldades, o projeto editorial foi interrompido. ${ }^{31}$

Convém ressaltar que a Revista converteu-se numa fonte inestimável de consulta sobre o Seminário, na medida em que ela veiculou as deliberações, bem como as comunicações e informes apresentados naquele evento. ${ }^{32}$ Em sua apresentação do primeiro número, Zea ${ }^{33}$ destacou a carência e dispersão dos estudos que vinham sendo realizados no campo da história das ideias no continente. A ideia de se publicar uma revista que pudesse servir de instrumento para difundi-los e coordená-los, segundo o mexicano, vinha desde a criação do Comitê de História das Ideias em 1947, mas, por falta de recursos, inúmeras tentativas haviam fracassado. A realização do Seminário de Porto Rico, em 1956, teria fornecido a nova e definitiva oportunidade para a sua concretização. O objetivo da Revista, expresso no primeiro seu número, era se constituir num

órgano de información y de difusión de los trabajos que sobre el campo de la historia de nuestras ideas se realizan en nuestra América y en aquellos países en que estas mismas ideas han sido y son objeto de investigación. Se buscará, en primer lugar, la publicación de esquemas que abarquen, dentro de sus limitaciones, la historia total o parcial de ideas, el pensamiento o la filosofía de cada uno de nuestros países en sus diversas expresiones: estéticas, sociales, políticas, económicas, religiosas, etc. Y al lado de estos trabajos, ensayos, monografías, sobre aspectos determinados o concretos de esta historia, y reseñas de los libros que sobre esta misma historia se vayan publicando en nuestros países o en los países que están interesados por la historia de nuestras ideas. ${ }^{34}$

Nos objetivos propostos para a Revista, pode-se já identificar algumas linhas gerais mais significativas: em primeiro lugar, a reafirmação do limite imposto ao objeto de investigação, na insistente referência à história de nossas ideias, onde e por quem quer que fosse produzida; em segundo lugar, o vínculo e a identificação estabelecida entre história das ideias e história do pensamento (ou da filosofia), que expressam o modo peculiar com que os integrantes do movimento concebiam a filosofia, como expressão e a serviço de uma circunstância histórico-cultural concreta e não de

Romero (Argentina), João Cruz Costa y José Honorio Rodrigues (Brasil), Antonello Gerbi (Itália), Francisco Miró Quesada (Perú), Arturo Ardao (Uruguai), entre outros.

31 Uma edição facsimiliar desses dois primeiros números foi publicada em 1984, em Quito, com o apoio do Banco Central do Equador, dentro da série colección de Revistas Ecuatorianas, incluindo um interessante estudo introdutório do argentino Arturo Andrés Roig, no qual fez um instigante balanço sobre os últimos 25 anos do movimento latinoamericano de história das Ideias. ROIG, Arturo Andrés. La "Historia de las Ideas" cinco lustros después.

32 Com destaque para a publicação dos informes dos representantes das diversas comissões nacionais do Comitê de história das ideias, apresentados ao Seminário, bem como um anexo com uma lista completa, incluindo os dados biográficos dos participantes do referido evento. TORRE DE VILLAR, Ernesto. El primer Seminario de Historia de las Ideas en América.

33 ZEA, Leopoldo. Presentación. Revista de Historia de las Ideas, n.1, Quito, 1959, p.10.

34 ZEA, Leopoldo. Presentación, p.10-11. 
um universalismo abstrato e hegemônico. E, por último, a consideração da possibilidade - e talvez mesmo necessidade - de tratamento das ideias em suas múltiplas expressões: estéticas, sociais, políticas, econômicas e religiosas, tema que $\mathrm{ArdaO}^{35}$ irá retomar em um artigo teórico publicado no primeiro número da Revista.

Cumpre então nesse momento empreender uma breve análise do conjunto das comunicações apresentadas no Seminário e posteriormente publicadas no primeiro volume da Revista. ${ }^{36} \mathrm{~A}$ maioria dos autores é formada por filósofos vinculados ao meio acadêmico, procedentes de vários países americanos, ${ }^{37}$ incluindo os Estados Unidos e Porto Rico - o que denota o propósito de extensão do movimento ao âmbito continental, ou seja, para além das fronteiras meramente ibero-americanas. Quanto ao perfil dos artigos, destacamos um primeiro e pequeno grupo de textos mais teóricos (Arturo Ardao, Santiago Vidal Muñóz e Humberto Piñera Llera) e um segundo grupo que privilegiou a temática das visões recíprocas entre os pensadores europeus e americanos (Antonello Gerbi e Francisco Miró Quesada). Havia ainda um terceiro grupo predominante de textos que apresentou um panorama da história das ideias em países específicos das Américas (Max Savelle, Abelardo Villegas, Benjamín Carrión, além de outros autores portoriquenhos), sendo que poucos deles estabelecem uma relação da produção local com a continental (Diego Domínguez Caballero e João Cruz Costa).

No primeiro grupo, Ardao abre o primeiro volume da Revista com um artigo intitulado Sobre el concepto de Historia de las Ideas, a partir do qual ele começa a se destacar como um dos principais teóricos do movimento, ao explorar questões cruciais no que tange aos fundamentos teóricometodológicos da nova disciplina história das ideias. Na verdade, o filósofo uruguaio já vinha dando enorme contribuição seja na produção de estudos sobre o pensamento e a filosofia no seu país, seja no processo de projeção e organização institucional do movimento em escala continental.

35 ARDAO, Arturo. Sobre el concepto de Historia de las Ideas. Revista de Historia de las Ideas, n.1, Quito, 1959, p.67-77.

36 Segue a lista completa desses trabalhos: Sobre el concepto de Historia de las Ideas, Arturo Ardao; Historia de las Ideas como Problema de la Filosofía de la Historia, Santiago Vidal Muñoz; La Visión Europea de los Pensadores Americanos, Antonello Gerbi; El filósofo Europeo visto por el Latinoamericano, Francisco Miró Quesada; América en la Historia, Leopoldo Zea; La Historia de las Ideas y la Realidad Americana, Humberto Piñera Llera; Preámbulos para una Historia de las Ideas en Puerto Rico, Monelisa Pérez Marchand; Notas para organizar el Estudio de las Ideas en Puerto Rico, Domingo Marrero Navarro; La Historia de las Ideas en los Estados Unidos, Max Savelle; Esquema para una Historia de la Filosofía en México, Abelardo Villegas; Panamá y la Historia de las Ideas en Latinoamérica, Diego Domínguez Caballero; Historia das Ideias no Brasil, seu desenvolvimento e suas relações com a história das ideias na América Espanhola, João Cruz Costa; Historia de las Ideas en el Ecuador, Benjamín Carrión; Apuntes para la Historia de las Ideas en América. El "Culto de la Conciencia" de Hostos, Adolfo de Hostos.

37 O único não americano, o italiano Antonello Gerbi, se notabilizou por seus vínculos com o continente americano - onde passou parte importante de sua vida - e pelo fato de sua obra no campo da história das ideias assumir a América como objeto e temática privilegiada. 
Outro artigo teórico, do investigador chileno Santiago Vidal Muñoz,38 além de defender o caráter historiável das ideias, nas suas diversas formas de expressão, destaca também aspectos conceituais, metodológicos e epistemológicos relativos à investigação no campo da história das ideias, na relação com a filosofia da história. ${ }^{39}$ Por ora vale destacar apenas como as questões de ordem terminológico-conceituais e as relacionadas à definição do objeto da nova disciplina já vinham sendo tratadas desde esse momento, em conformidade com os objetivos da Revista expressos por Zea e analisados anteriormente.

No segundo grupo de artigos, que enfocam as visões recíprocas entre os pensadores europeus e americanos, percebe-se a preocupação de colocar em questão as relações entre a filosofia e a cultura de ambos os continentes. Seja na denúncia da ignorância europeia frente à filosofia americana (Antonello Gerbi), seja na crítica da "admiração incondicional" dos filósofos latino-americanos pelo pensamento europeu (Francisco Miró Quesada), tais trabalhos visaram revalorizar a produção intelectual autóctone latino-americana, em busca de especificidades frente às matrizes do pensamento filosófico europeu. Nesse sentido, tais textos situam-se dentro do debate filosófico existente no contexto intelectual de emergência do movimento de história das ideias na América Latina.

Por fim, o terceiro grupo de artigos, ao tentar traçar o panorama ou estabelecer as bases para uma história das ideias na esfera de cada país, segue, em sua maioria, o mesmo paradigma disciplinar e a mesma inspiração temática estabelecidos por Zea em seus estudos anteriores sobre o positivismo no México e na Hispano-América.

O segundo número da Revista de Historia de las Ideas, publicado em 1960, dá continuidade à mesma linha editorial, apenas com a inclusão de artigos de outros autores de alguns países que não haviam estado representados no número anterior ${ }^{40}$ e nem haviam participado do Seminário. Em linhas gerais, tal como no número anterior, tanto as temáticas quanto as abordagens da maioria dos textos se aproximam do modelo zeano.

O artigo teórico que abre esse número, escrito pelo investigador mexicano Abelardo Villegas (1934-2000) - um ex-aluno de Zea -, intitulado Esquema para la elaboración de una idea de la Historia de las Ideas en América, de

38 VIDAL MUÑOZ, Santiago. Historia de las Ideas como Problema de la Filosofía de la Historia. Revista de Historia de las Ideas, 1959, p.79-90.

39 O próprio autor reconhece em nota que suas reflexões nesse artigo se inspiraram na temática do Seminario de filosofía de la historia do professor Félix Schwartzmann, ministrado no Chile em 1956 VIDAL MUÑOZ, Santiago. Historia de las Ideas como Problema de la Filosofía de la Historia, p.79.

40 Segue a lista completa dos artigos publicados nesse volume: Esquema para la elaboración de una idea de la Historia de las Ideas en América, Abelardo Villegas; Elements of Transcendentalism in Latin American, John Sterling Harris; Ideario Americanista de don Juan de Egaña, Raúl Silva Castro; Las Ideas Liberales en el Ecuador - Breve esquema para su Historia, Gabriel Cevallos García; El Despertar Positivista, Arturo Uslar Pietri; En torno a las Ideas en Colombia - Del Positivismo a la Neoescolástica, Jaime Jaramillo; Influencias ideológicas en Centro América, Rafael Heliodoro Valle. 
natureza eminentemente terminológico-conceitual, enfoca e relaciona os conceitos de história e de história das ideias, voltando-se para o objeto dessa última, as ideias, ressaltando a sua historicidade e seu caráter objetivo. ${ }^{41}$ Tal artigo é mais um exemplo de certa preocupação do grupo em estabelecer alguns fundamentos teórico-metodológicos para a nova disciplina história das ideias, em particular no que diz respeito à delimitação e caracterização de seu próprio objeto de estudo.

Se Ardao havia considerado os anos 40 como a década fundadora do movimento latino-americano de história das ideias, a realização do Seminário de História das Ideias na América, em 1956, significou para ele o "certificado de maioridade do movimento", servindo para determinar suas diretivas fundamentais. ${ }^{42}$ Além de promover o intercâmbio e a articulação entre diversos investigadores latino-americanos, o evento contribuiu para apontar alguns dos principais objetos de estudo dessa proposta latino-americana de história das ideias. Por outro lado, contribuiu também para definir, por meio dos principais trabalhos nele apresentados, as linhas gerais de um programa de orientação teórico-metodológica para o desenvolvimento e a prática de uma história das ideias na América. ${ }^{43}$

A publicação dos números iniciais da Revista de Historia de las Ideas, como órgão de difusão dos estudos nesse campo, além das comunicações apresentadas no Seminário, representou o complemento editorial de tal projeto. Assim, esses dois marcos, o Seminário e a Revista, abriram uma nova etapa de consolidação do movimento latino-americano de história das ideias. Por outro lado, como consequência desse processo de consolidação que tomou corpo a partir das décadas de 1940 e 1950, Roig considerou que a história das ideias acabou por tornar-se não apenas uma forma de saber disciplinar, mas uma "corrente de pensamento". Em outras palavras, organizou-se a partir de então uma historiografia que implicava uma tomada de posição teórica com respeito à realidade social e nacional na América Latina. ${ }^{44}$

Enfim, foi em torno da liderança de Leopoldo Zea que se constituiu e se consolidou na América Latina, em meados do século XX, um movimento

41 VILLEGAS, Abelardo. Esquema para la elaboración de una idea de la historia y de una Historia de las Ideas en América. Revista de Historia de las Ideas, n.2, Quito, 1960, p.11.

42 ARDAO, Arturo. Apud: ROIG, Arturo Andrés. La "Historia de las Ideas" cinco lustros después, p.VI.

43 Entretanto, Ardao, ao fazer um balanço do referido Simpósio - registrado em um texto de 1959 e incluído posteriormente na publicação de seu livro Filosofía de lengua española (1963) -, considerou que as motivações do movimento, cuja expressão coletiva mais importante era representada por esse evento, não eram puramente acadêmicas. No fundo, o que estava em questão, segundo ele, era o problema da América, da sua natureza e destino como entidade histórica, um problema, enfim, do homem e do espírito americanos. Eram as demandas, de um lado, por investigar as correntes de ideias que impulsionaram o processo de formação das nações da América, como meio de conscientização de sua força e de seu lugar no mundo e, de outro, por estabelecer o papel histórico da consciência americana de seus autênticos modos de pensar. Essa preocupação americanista, típica do século XX, teria encontrado no movimento americano de história das ideias, ainda segundo Ardao, se não o único, um dos mais ativos órgãos de recepção e manifestação de tais inquietudes e tendências. ARDAO, Arturo. Filosofía en lengua española. Montevideo: Editorial Alfa, 1963

44 ROIG, Arturo Andrés. La "Historia de las Ideas" cinco lustros después, p.VIII. 
intelectual que significou muito mais do que uma mera corrente ou vertente particular da história das ideias. Tratou-se mesmo de um movimento, organizado e articulado, que associou o seu projeto de uma história das ideias latino-americana a uma perspectiva de autoafirmação nacional e continental. Entre outras atividades, tal movimento fundou destacadas organizações e instituições - dentro e fora dos meios universitários -, produziu e incentivou um número significativo de eventos e de publicações, sempre com o propósito de promover o intercâmbio e a articulação dos inúmeros investigadores que atuavam na área da história das ideias na América Latina. Mas, também, um movimento que, por outro lado, utilizando desses meios, procurou sugerir e implementar um determinado programa de orientação dos estudos latino-americanos no campo das ideias, segundo certos pressupostos teóricos, metodológicos, filosóficos e epistemológicos relativamente claros. 